\title{
Factor Analysis and Psychometric Properties Adaption of Chinese Version of the Decisional Engagement Scale (DES-I0)
}

This article was published in the following Dove Press journal: Patient Preference and Adherence

\author{
Feijie Wang ${ }^{1, *}$ \\ Lijie Huang ${ }^{1} *$ \\ Hongmei Zhang ${ }^{2}$ \\ Hongxia Jiang' \\ Xiaoxia Chang' \\ Yinping Chu' \\ Zhixia Wang ${ }^{3}$ \\ Xiaoli Zhang'
}

'Department of Urinary Surgery, Henan Provincial People's Hospital, Zhengzhou University Peoples Hospital, Zhengzhou, Henan 450003, People's Republic of China; ${ }^{2}$ Nursing Department, Henan Provincial People's Hospital, Zhengzhou University People's Hospital, Zhengzhou, Henan 450003, People's Republic of China; ${ }^{3}$ Gastrointestinal Surgery, Henan Provincial People's Hospital, Zhengzhou University People's Hospital, Zhengzhou, Henan 450003, People's Republic of China

*These authors contributed equally to this work
Correspondence: Hongmei Zhang Email zI26hm@I26.com
Objective: To translate and validate the DES-10 into Chinese and adapt the DES-10 among Chinese prostate cancer patients. To explore the impact of demographic data on the SDM of Chinese prostate cancer patients.

Methods: Data were collected from December 2019 to January 2020 from four hospitals among prostatic cancer patients in Henan Province, by convenience sampling method. A demographic questionnaire, DES-10, and 9-item Shared Decision Making Questionnaire (SDM-Q-9) were administered. The exploratory and confirmatory factor analysis was carried out to test the content, construct, reliability, and concurrent validity of the translated DES- 10 . Then, Pearson's correlation, $t$-test, and analysis of variance were used to test the demographic difference of DES-10.

Results: A total of 380 prostatic cancer patients completed the survey ( $96 \%$ response rate). The total score of DES-10 was $71.16 \pm 17.14$. The Cronbach's a coefficient was 0.87 . Single factor structure was confirmed by exploratory factor analysis (explaining $50.14 \%$ of the variance). Model fitting indexes (RMSEA=0.07, $\mathrm{CMIN} / \mathrm{DF}=2.92$ ) were acceptable. The DES-10 scale showed good validity with the SDM-Q-9 as the criterion. Age, marital status, homeplace, and household monthly income could affect the shared decision-making of prostatic cancer patients.

Conclusion: The DES-10 was demonstrated to be a valid and reliable scale to assess the prostatic cancer patient's engagement in health care decision-making. And it is culturally appropriate for use in China. The influence of age, marital status, homeplace, and household monthly income should be considered in promoting patients' participation in shared decision-making.

Keywords: reliability, decisional engagement scale, prostatic cancer patients

\section{Introduction}

Prostate cancer (PCa) was the second most common cancer, ${ }^{1}$ which caused $6.6 \%$ of the total deaths of men, ranking fifth in leading cancer-related deaths in men worldwide. ${ }^{2}$ The incidence of prostate cancer is increasing in most Asian countries especially in people with Chinese ancestry, and the mortality rates have also increased in China. ${ }^{3}$ Nowadays, alternative treatments are used in prostate cancer treatment, ${ }^{4}$ such as watchful waiting, active surveillance, surgery, chemotherapy, etc. Surgery and chemotherapy could help certain patients survive the disease, while with side effects like impaired urinary function, ${ }^{5}$ sexual dysfunction, ${ }^{6}$ and lower quality of life. $^{7}$ Active surveillance might be a preferable choice for patients with low-risk 
disease, ${ }^{8}$ and watchful waiting could help patients with intermediate-risk disease to achieve satisfactory quality of life. ${ }^{9}$ However, because of the absence of an optimal treatment strategy regarding prostate cancer, patients have to make critical and highly preference-sensitive decisions involving trade-offs between benefits and potential risks. ${ }^{10}$ Shared decision-making (SDM) was recommended as a fundamental process in doctor-patient interaction in treatment decisions. ${ }^{11}$

SDM was defined as a dynamic process in which patients and health care providers jointly make the best health decisions, ${ }^{12}$ based on the aggregation of medical evidence and patient values, and highlights the ethical principle of respecting autonomy. ${ }^{13}$ The health professionals were encouraged to respect consumers' preferences and share the decision-making responsibility with them in the process of SDM. ${ }^{14}$ Nowadays, SDM is being used in maternal-fetal care, stable ischemic heart disease, orthopedics surgery, and prostate cancer treatment. ${ }^{15,16}$ SDM could increase disease-related knowledge and help patients make clinical decisions aligned with their self preferences. ${ }^{17}$ Related studies had demonstrated that medical information itself could not help patients improve their health, but patient engagement in their health decisions based on medical information would lead to better health care quality and efficiency. ${ }^{18} \mathrm{SDM}$ could increase patients' compliance with treatment, ${ }^{19}$ improve health care outcome, ${ }^{20}$ and save on medical costs. ${ }^{21}$ The existing evidence has shown that the more engagement in the decision-making process, the less stress of decisionmaking for cancer patients. ${ }^{22}$ A study suggested that the desire to participate in health care decision-making is particularly strong in samples of cancer patients. ${ }^{23}$ Another study conducted in a tumor hospital from Guangzhou reported that $71.85 \%$ of the investigated patients believed that SDM was essential. ${ }^{24}$ Since the importance of the health care decision-making process in cancer therapy was well-documented, a tool to measure prostate cancer patients' engagement in the health care decision-making process is necessary. Multiple measuring scales have been developed through easy-to-approach questionnaires for SDM. However, many of them are too general. The 10-item Decisional Engagement Scale (DES-10) had been confirmed by prostate cancer patients regarding its good reliability and validity, and it was able to measure the degree of health care decision-making for them. $^{25}$
The 10-item scale is a self-reporting instrument and has a stable and simple structure, excellent reliability and validity. The internal consistency reliability was 0.80 among 376 patients with prostate cancer. ${ }^{25}$ Currently, SDM-Q-9 was translated and used among the in-patients in China and has been proven to be a reliable and eligible tool to assess the patient's perspective in the process of SDM in a clinical situation, but the scale is not specifically for prostate cancer patients, and the correlation of testretest reliability is relatively low. $^{26}$ Few generally accepted, culturally appropriate scales exist to accurately measure prostate cancer patients', engagement in shared decision-making process in China, therefore, it is critical to identify such a tool. To the best of our knowledge, this is the first time in literature that the Chinese 10-item Decisional Engagement Scale (DES-10-Chinese) has been adapted among Chinese prostate cancer patients to demonstrate its reliability and validity.

\section{Methods}

\section{Study Design}

One cross-sectional study was conducted from December 2019 to January 2020 in four hospitals in Henan Province, the central part of People's Republic of China.

\section{Sample}

Four tertiary grade A hospitals were picked by convenience sampling method, which have more than 501 hospital beds, provide specialty medical and health services, and conduct advanced educational and scientific research tasks. $^{27}$ The total number of participants was determined by the Kendall criterion ${ }^{28}$ (i.e., 5-10 fold the number of items). Since there are 24 items in total, including demographic information (5 items), 10-item Decisional Engagement Scale (DES-10) and 9-item SDM-Q-9, 120-240 participants were needed. Considering 20\% convenience sampling error, 144-288 participants were essential in this study. Finally, 396 newly admitted prostate cancer in-patients were investigated from four of the previously mentioned hospitals, and 380 of them completed the survey with a response rate of $96.0 \%$. After admission to hospitals, these patients may face watchful waiting, active surveillance, surgery, chemotherapy, etc. The study criteria were as follows, inclusion criteria: a) diagnosed with prostate cancer confirmed by clinicopathological examination; b) had known the diagnosis, and no barrier 
in communicating; c) voluntary participation in research. Exclusion criteria: a) patients with mental disorders, senile dementia, and consciousness disorders; b) with severe heart, brain or lung disease and tumor metastasis. Written informed consent was obtained from all participants before the data collection interview took place.

\section{Measures}

The questionnaire included three parts: the demographic information, 10-item Decisional Engagement Scale (DES-10), and the 9-item Shared Decision Making Questionnaire (SDM-Q-9).

\section{The Demographic Information}

The general information included demographic variables: age, marital status, educational level, family residence, and household monthly income.

\section{Des- 10}

DES-10 was a 10-item, single-factor measure of cancer patients' engagement in the health care decision-making process, "which was able to well assess patients' awareness of their diagnosis, sense of empowerment and involvement, and level of information-seeking and planning". 25 The DES-10 used an 11-point Likert-type scale ranging from 0 (totally disagree) to 10 (totally agree) with a total score of $0 \sim 100$. A higher total score indicated greater engagement in decision-making in cancer care.

\section{Sdm-Q-9}

SDM-Q-9 was a 9-item, single-factor measure. ${ }^{26}$ A 6-point Likert-type scale ranging from 0 (totally disagree) to 5 (totally agree) with a total score of $0 \sim 45$. SDM-Q-9 was able to be used to assess the patients' perspective in the process of SDM in clinical situations. The author suggested converting the original score $0 \sim 100$ by multiplying 20/9 for easy comparison. The Cronbach's a of SDM-Q-9 was 0.97 in this study.

\section{Translation Procedure}

The DES-10 scale was authorized by Doctor Michael Hoerger, $^{25}$ and the translation process was composed of several steps based on the Brislin translation model (Brislin, 1970). ${ }^{29}$ Firstly, the DES-10 was translated from English into Chinese by two bilingual professional translators. A group of bilingual experts, including two psychology experts and two nursing experts, was organized to review the translated version concerning its content accuracy, semantic equivalence, and sentence structure.
Secondly, the Chinese version was translated back into English by another two, who had not been exposed to the original scale, and they worked respectively between the forward and back translation process. Then experts including one sociology professor, two psychology experts, and two nursing experts were invited to evaluate each item of the scale one by one from the aspects of articulation, language habits, cultural and linguistic equivalence, to fully ensure the cultural relevance and content equivalence of the Chinese version of DES-10. Then we got the trial DES-10-Chinese, after making some minor revisions. Thirdly, the pilot study was carried out among 20 Chinese prostate cancer patients, the results showed the Cronbach's a was 0.86 , reflecting an acceptable internal consistency, and both interviewees and interviewers were able to understand questions of the scale, and discrepancies were adjusted based on the participants' feedback on the items. Lastly, we acquired the final Chinese version of DES-10, which was explicit, easy to understand, and had cultural equivalence.

\section{Data Collection}

The data were collected from December 2019 to January 2020 in in-patient wards in Henan Province by 10 wound and stoma therapists. Before conducting the oneon-one, face-to-face survey, they were all trained in a preliminary pilot study. 380 participants completed the survey anonymously. The longer the interval for measurement, the lower is the stability coefficient, so the recommended reliable interval is 1-2 weeks. $^{30}$ After data collection and encoding, 60 of them were randomly sampled after 1 week to test the test-retest reliability of the scale.

\section{Ethics}

This study was approved by the Ethical Review Board of Henan Provincial People's Hospital (2019 Ethics No. 74), Zhengzhou, China, and was in accordance with the Declaration of Helsinki. All participants knew the purpose of the study, and all agreed to participate.

\section{Data Analyses}

Data analysis was conducted with SPSS21.0 and AMOS22.0. The internal consistency of the DES-10 was estimated by Cronbach's $\alpha$. The test-retest correlation coefficient (Intra-class Correlation Coefficient, ICC) was used to calculate the scale's stability. The content validity was analyzed by item-total and inter-item correlations, and five experts were also invited to evaluate the content 
validity index (CVI) of DES-10, each of them marked each item based on the four grades: 4=very relevant; $3=$ strong correlation; $2=$ weak correlation; and $1=$ not related; very relevant and strong correlation were transformed to score of 1 , and not related and weak correlation were transformed to score of $0 .^{31} 50 \%$ of the data was randomly selected for exploratory factor analysis (EFA), and the remaining data were used for validity factor analysis (CFA) to test scale validity. Besides, Pearson's correlation between DES-10-Chinese and SDM-Q-9 was calculated to estimate the concurrent validity, $\mathrm{P}<0.05$ was defined as statistically significant.

Then, $t$-test and analysis of variance were used to test the demographic difference (marital status, homeplace, education level, and monthly household income) in DES10. Pearson's correlation was used to analyze the relationship between age and DES-10.

\section{Results}

\section{The Sample}

The age of the 380 participants ranged from 25 to 79 , with a mean value of $59.77 \pm 11.42$. The total scores of DES-10 and SDM-Q-9 were (71.16 \pm 17.14$),(78.29 \pm 20.54)$, respectively (Table 1). The detailed demographic information was shown in Table 2.

\section{Reliability}

Cronbach's a was used to assess the internal consistency. The psychometric testing results showed a one-factor structure and high internal consistency in the final Chinese edition of DES-10 with a total Cronbach's a of 0.87 . The inter-item

Table I Item-to-Total Score Correlations for the DES-I0

\begin{tabular}{|c|c|c|c|c|}
\hline Items & $\mathbf{X} \pm \mathbf{S}$ & $\begin{array}{l}\text { Cronbach's } \\
\alpha \text { if Item } \\
\text { Deleted }\end{array}$ & ICC/95\% Cl(n=60) & $\begin{array}{l}\text { Item-to-Total } \\
\text { Correlation } \\
\text { Coefficient }\end{array}$ \\
\hline I & $5.83 \pm 3.19$ & 0.85 & $0.994 *(0.990 \sim 0.997)$ & $0.80 *$ \\
\hline 2 & $5.52 \pm 2.92$ & 0.86 & $0.949 *(0.913 \sim 0.970)$ & $0.74 *$ \\
\hline 3 & $6.68 \pm 3.36$ & 0.85 & $0.999 *(0.998 \sim 0.999)$ & $0.82 *$ \\
\hline 4 & $7.07 \pm 2.80$ & 0.86 & $0.976 *(0.957 \sim 0.986)$ & $0.68 *$ \\
\hline 5 & $7.04 \pm 3.06$ & 0.86 & $0.989 *(0.980 \sim 0.994)$ & $0.75 *$ \\
\hline 6 & $8.72 \pm 1.25$ & 0.88 & $0.686 *(0.381 \sim 0.830)$ & $0.40^{*}$ \\
\hline 7 & $8.79 \pm 1.94$ & 0.85 & $0.973 *(0.932 \sim 0.987)$ & $0.8 I^{*}$ \\
\hline 8 & $9.26 \pm 1.29$ & 0.86 & $0.98 I *(0.965 \sim 0.990)$ & $0.76 *$ \\
\hline 9 & $8.77 \pm 1.53$ & 0.87 & $0.989 *(0.980 \sim 0.993)$ & $0.55^{*}$ \\
\hline 10 & $3.49 \pm 2.79$ & 0.87 & $0.974 *(0.956 \sim 0.984)$ & $0.64 *$ \\
\hline
\end{tabular}

Note: $P *<0.01$. correlations ranged from 0.18 to 0.70 , the item-to-total correlations ranged between 0.40 and 0.82 .

After 1 week of investigation, 20 patients who had participated in this study were randomly selected for the retest, and the retest reliability coefficient was $0.98(95 \%$ CI, 0.94-0.99, $\mathrm{P}<0.001$ ) (Table 1).

\section{Validity}

\section{Content validity}

The average CVI in this study was 0.86 , five experts provided the values of every item, ranging from 0.83 to 1.00 .

\section{Construct Validity}

In EFA, the Kaiser-Meyer-Olkin (KMO) was 0.92, with a Bartlett spherical test value of $1658.43(\mathrm{P}<0.001)$, which showed that the data could be used for principal component analysis (PCA). PCA extracted one factor with eigenvalue $>1.00$, which explained $50.14 \%$ of the total variance, as was shown in Figure 1. In CFA, the indices of the structural equation model (SEM) of DES-10 were very good. SEM revealed CMIN/DF $=2.92$, RMSEA $=0.07$, $\mathrm{CFI}=0.96, \mathrm{AGFI}=0.93, \mathrm{GFI}=0.95, \mathrm{TLI}=0.95$. The SEM and standardized regression coefficients of onefactor model were shown in Figure 2.

\section{Concurrent Validity}

With SDM-Q-9 as criterion, the correlation between SDMQ-9 and DES-10-Chinese was high $(r=0.88, \mathrm{P}<0.001)$. The correlation coefficient between items of DES-10-Chinese and total score of SDM-Q-9 ranged between 0.33 to 0.73 , item 6 (I would prefer to discuss treatment goals and options sooner rather than later) had the weakest correlation with SDM-Q-9 ( $\mathrm{r}=0.33, \mathrm{P}<0.01)$, and item 3 (I feel confident in my ability to make decisions about medical treatments) had the strongest correlation with SDM-Q-9 $(r=0.73, P<0.01)$.

\section{Demographic Difference}

There was a correlation between age and DES-10-Chinese $(\mathrm{r}=-0.23, \mathrm{P}<0.001)$. The engagement in shared decisionmaking varied by marital status, homeplace, and household monthly income, and the difference was statistically significant $(\mathrm{P}<0.05)$. The comparison of general demographic information was shown in Table 2.

\section{Discussion}

A reliable method to conduct the cross-cultural adaptation of the DES-10-Chinese is critical, and the scale must be 
Table 2 Demographic Difference of DES-I0 $(n=380)$

\begin{tabular}{|c|c|c|c|c|c|}
\hline Variables & $\mathbf{N}(380)$ & Constituent Ratio (\%) & DES-10 (Mean $\pm S D)$ & $F / t$ & $\mathbf{P}$ \\
\hline \multicolumn{6}{|l|}{ Marital status } \\
\hline Current spouse & 372 & 97.90 & $61.64 \pm 11.97$ & 3.39 & 0.000 \\
\hline Deceased spouse & 8 & 2.10 & $51.13 \pm 28.47$ & & \\
\hline \multicolumn{6}{|l|}{ Homeplace } \\
\hline Rural areas & 250 & 65.80 & $69.76 \pm 17.53$ & -2.23 & 0.017 \\
\hline Urban areas & 130 & 34.20 & $73.87 \pm 16.08$ & & \\
\hline \multicolumn{6}{|l|}{ Education } \\
\hline Junior high school and below & 266 & 70.00 & $69.97 \pm 17.93$ & 2.20 & 0.050 \\
\hline High School or Technical School & 59 & 15.50 & $75.95 \pm 11.35$ & & \\
\hline Graduate and above & 55 & 14.50 & $71.82 \pm 20.57$ & & \\
\hline \multicolumn{6}{|l|}{ Household monthly income } \\
\hline$\leqq 2000$ & $17 \mid$ & 45.00 & $69.68 \pm 15.68$ & 6.29 & 0.000 \\
\hline $200 \mathrm{I} \sim 4000$ & 132 & 34.80 & $74.20 \pm 16.38$ & & \\
\hline $4001 \sim 6000$ & 56 & 14.70 & $65.14 \pm 21.88$ & & \\
\hline$\geqq 6001$ & 21 & 5.50 & $80.14 \pm \mid 1.68$ & & \\
\hline
\end{tabular}

proven to be reliable by statistical analysis before it could be used as a method for patients' evaluation. ${ }^{32}$ The previously mentioned results showed a successful adaption process among Chinese prostatic cancer patients. This unidimensional DES-10-Chinese scale could evaluate the engagement in decision-making for prostate cancer patients specifically.

In this work, the Cronbach's a of DES-10 was 0.87 , which is satisfactory, for the Cronbach's a coefficient between 0.70 and 0.90 was recommended when assessing an instrument, ${ }^{33}$ and the results showed better internal consistency than the American version (0.80). ${ }^{25}$ The Cronbach's a coefficient did not improve after deleting items of DES-10, except item 6. Item 6 "I would prefer to discuss treatment goals and options sooner rather than later" identified the earnest willingness of the prostatic cancer patients to receive quick treatment after admission. Studies have shown that "discuss treatment goals and options" was the primary concern for most Chinese patients, because of the fear of progression and recurrence. ${ }^{34}$ Although there existed some limitations of item 6 concerning the reliability, we recommend not deleting it given its practical significance.

The test-retest ICC of DES-10-Chinese was 0.98, which met the recommended criterion of 0.90 , representing good stability, for ICC ranging from $0.00-0.20$ indicated slight agreement, $0.21-0.40$ for fair agreement, $0.41-0.60$ for moderate agreement, $0.61-0.80$ for substantial agreement, and $0.81-1.00$ for almost perfect agreement. ${ }^{35}$ And the results supplemented the test-retest reliability for the original English version of DES-10. The CVI was 0.86, indicating good content validity. ${ }^{36}$ After repeated cultural adjustment, the DES-10-Chinese had good content validity and achieved the equivalence of the original scale in terms of concept, semantics, and content.

EFA was conducted to estimate the construct validity of DES-10-Chinese, item loading ( $\geqq 0.40)$ on one of the common factors was suggested as an ideal factor, and the cumulative variance contribution ratio of the common factor was $\geqq 40 \% .{ }^{37}$ In EFA one factor was explored, which contributed $50.14 \%$ of the total variance, and the loading value of each item ranged from $0.40-0.84$, indicating acceptable construct validity. Then the CFA was constructed to verify the validity of the scale, fit indexes showed the explained variances strongly agreed with the EFA, and the DES-10-Chinese was demonstrated to be a one-factor structure. Pearson's correlations were utilized to verify the concurrent validity of DES-10-Chinese and there was a correlation between SDM-Q-9 and DES-10Chinese $(\mathrm{r}=0.88, \mathrm{P}<0.001)$, which indicated good concurrent validity in the expected direction. ${ }^{38}$ These results showed good validity and reliability to assess the patients' engagement in shared decision-making.

Table 2 showed that several sociodemographic variables such as age, marital status, homeplace, and household monthly income were correlated with DES-10. Age was negatively correlated with DES-10, the older, the less participation in SDM, which was in accordance with the 


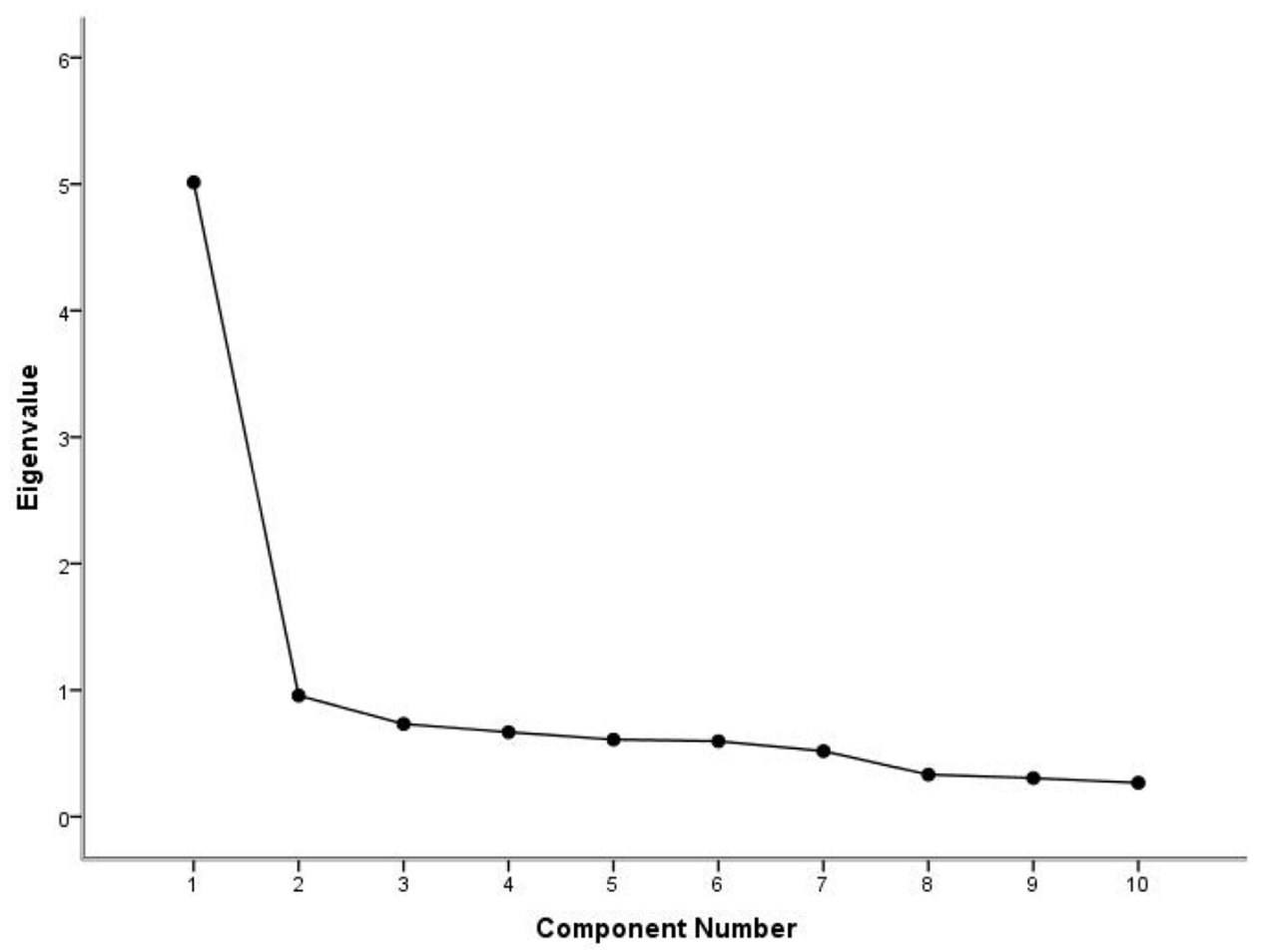

Figure I Lithotripsy map of principal component analysis for Chinese version of the DES-I0 $(n=190)$.

previous study. ${ }^{25}$ The study of Haesebaert et $\mathrm{al}^{39}$ showed that age could affect patients' decision participation, and participants aged $\geqq 65$ years experienced the least shared decision-making. DES-10 scores of patients with current spouses were higher than those of patients with deceased spouses, which was consistent with the study of Rose et $\mathrm{al}^{40}$ which stated that family support was able to encourage frail elderly patients to make shared decisions on rehabilitation options. In the study of Zhai et al, ${ }^{41}$ Chinese colorectal cancer surgery patients tended to rely more on close family members to make decisions. Patients from rural areas showed less participation in SDM than those in urban areas. The study of Shi et $\mathrm{al}^{42}$ found that urban patients had easier access to information than rural patients, more thorough understanding of tumorrelated knowledge, and stronger desire to know about their condition. Higher income could promote SDM participation. Cancer patients usually suffer from high medical expenses, which would affect the treatment choice and hinder their access to relevant medical services. The lower the family's annual income, the more likely they were to adopt simple surgical treatment. For high-income cancer patients, their financial status and social networks enabled them to seek more treatment options. ${ }^{43}$ These results suggest that we should pay more attention to the older, lower-income, widowed, and rural patients, when making shared decisions.

This research is limited in several aspects. Firstly, in the measuring process of the retest reliability, only a small group of participants were included, and the telephone combined with WeChat replaced the face-to-face interviews the second time. Therefore, some divergence might exist between the two investigations. Secondly, the patients who were included in this study were all inpatients at large academic hospitals in China, which could have potential selection bias given the high likelihood that these patients are more educated and have more resources than patients treated in the smaller community hospitals. Thirdly, the study did not verify the sensitivity and specificity, for picking an appropriate cutoff value for identifying lower SDM prostate cancer patients. A future study could recruit a larger number of participants to explore the cut-off value and further confirm the reliability and validity of DES-10-Chinese for prostatic cancer patients in other settings in China. Moreover, we may need to adapt this scale in a different population of patients or in a setting outside of the academic hospitals to ensure its external validity. Furthermore, other related factors should be added to 


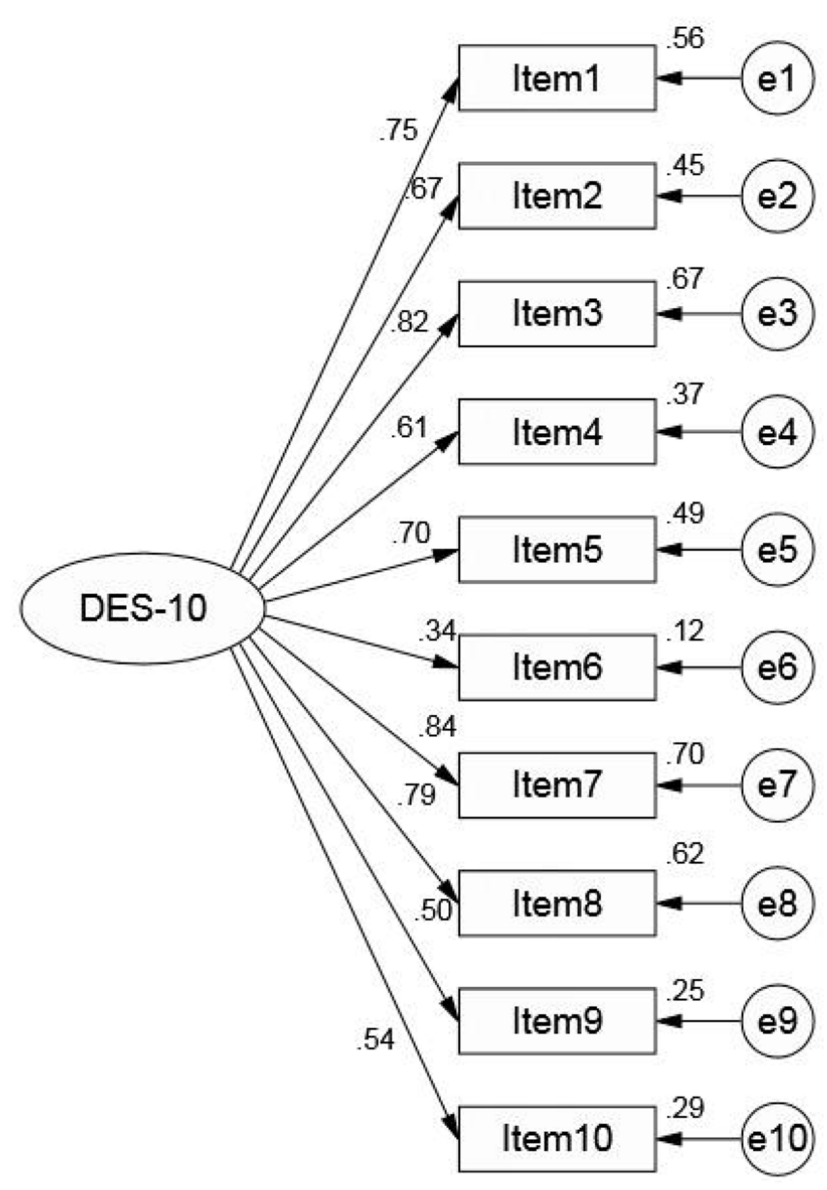

Figure 2 Standardized one-factor structural model of the DES-10 $(n=190)$.

improve the engagement of SDM for Chinese prostatic cancer patients.

\section{Conclusion}

It is the first time the DES-10 has been tested with respect to homogeneity, stability, content, and construct validity among Chinese prostatic cancer patients. The result of this research showed adequate evidence of stability and homogeneity, as well as of content and construct validity to assess the prostatic cancer patients' engagement in health care decision-making.

\section{Acknowledgments}

The authors are grateful to all the study participants in this study. Feijie Wang and Lijie Huang are co-first authors for this study.

\section{Funding}

There is no funding supports this study.

\section{Disclosure}

The authors stated that they have no conflicts of interest for this work.

\section{References}

1. Castillejos-Molina RA, Gabilondo-Navarro FB. Prostate cancer. Salud Publica Mex. 2016;58(2):279-284. doi:10.21149/spm. v58i2.7797

2. Zhou Y, Guan H, Fu Y, et al. The impact of pre-existing cancer on survival of prostate cancer patients: A population-based study. Medicine. 2018;97(50):e13479.

3. Kimura T, Egawa S. Epidemiology of prostate cancer in Asian countries. Int J Urol. 2018;25(6):524-531. doi:10.1111/iju.13593

4. Adolfsson J. Treatment of Localized Prostatic Cancer-Different Alternatives. Patients With Localized Prostatic Cancer Must Actively Participate in the Choice of Therapy. Lakartidningen. 2000;97(36):3870-3874.

5. Jarosek SL, Virnig BA, Chu H, Elliott SP. Propensity-weighted long-term risk of urinary adverse events after prostate cancer surgery, radiation, or both. Eur Urol. 2015;67(2):273-280. doi:10.1016/j. eururo.2014.08.061

6. Zhu Z, Zhang J, Liu Y, Chen M, Guo P, Li K. Efficacy and toxicity of external-beam radiation therapy for localised prostate cancer: a network meta-analysis. Br J Cancer. 2014;110(10):2396-2404. doi:10.1038/bjc.2014.197

7. Charalambous A, Kouta C. Cancer Related Fatigue and Quality of Life in Patients with Advanced Prostate Cancer Undergoing Chemotherapy. Biomed Res Int. 2016;2016:3989286.

8. J D G, Klotz L. Active Surveillance for Prostate Cancer: how to Do It Right. Oncology. 2017;31(5):333-340.

9. Bill-Axelson A, Holmberg L, Garmo H, et al. Radical prostatectomy or watchful waiting in early prostate cancer. $N$ Engl J Med. 2014;370 (10):932-942. doi:10.1056/NEJMoa1311593

10. Martínez-González NA, Plate A, Senn O, Markun S, Rosemann T, Neuner-Jehle S. Shared decision-making for prostate cancer screening and treatment: a systematic review of randomised controlled trials. Swiss Med Wkly. 2018;148:w14584.

11. Martínez-González NA, Plate A, Markun S, Senn O, Rosemann T, Neuner-Jehle S. Shared decision making for men facing prostate cancer treatment: a systematic review of randomized controlled trials. Patient Prefer Adherence. 2019;13:1153-1174. doi:10.2147/ PPA.S202034

12. Elwyn G, Frosch D, Thomson R, et al. Shared Decision Making: A Model for Clinical Practice. J Gen Intern Med. 2012;27 (10):1361-1367. doi:10.1007/s11606-012-2077-6

13. Charles C, Gafni A, Whelan T. Shared decision-making in the medical encounter: what does it mean? (or it takes at least two to tango). Soc Sci Med. 1997;44(5):681-692. doi:10.1016/S0277-9536(96) 00221-3

14. Marie TL, Jason TS. Shared Decision-Making for Nursing Practice: an Integrative Review. Open Nurs J. 2018;12:1-14.

15. Elwyn G, Frosch DL, Kobrin S. Implementing shared decision-making: consider all the consequences. Implement Sci. 2016;11(1):114. doi:10.1186/s13012-016-0480-9

16. Spatz ES, Krumholz HM, Moulton BW. Prime Time for Shared Decision Making. JAMA. 2017;317(13):1309-1310. doi:10.1001/ jama.2017.0616

17. Barry MJ, Edgman-Levitan S. Shared decision making-The pinnacle of patient-centered care. N Engl J Med. 2012;366(9):780-781. doi:10.1056/NEJMp1109283

18. Williams N, Fleming C, Doubleday A. Patient and provider perspectives on shared decision making: a systematic review of the peer-reviewed literature. J Comp Eff Res. 2017;6(8):683-692. doi:10.2217/cer-2017-0045 
19. Raue PJ, Schulberg HC, Bruce ML, et al. Effectiveness of Shared Decision-Making for Elderly Depressed Minority Primary Care Patients. Am J Geriatr Psychiatry. 2009;27(8):883-893. doi:10. 1016/j.jagp.2019.02.016

20. Atherton PJ, Smith T, J A S, et al. The relation between cancer patient treatment decision-making roles and quality of life. Cancer. 2013;119(12):2342-2349. doi:10.1002/cncr.28046

21. Oshima Lee E, Emanuel EJ. Shared decision making to improve care and reduce costs. $N$ Engl J Med. 2013;368(1):6-8. doi:10.1056/ NEJMp1209500

22. Brown R, Butow P, Wilson-Genderson M, Bernhard J, Ribi K, Juraskova I. Meeting the decision-making preferences of patients with breast cancer in oncology consultations: impact on decision-related outcomes. J Clin Oncol. 2012;30(8):857-862. doi:10.1200/jco.2011.37. 7952

23. Chewning B, Bylund CL, Shah B, Arora NK, Gueguen JA, Makoul G. Patient preferences for shared decisions: a systematic review. Patient Educ Couns. 2012;86(1):9-18. doi:10.1016/j.pec.2011.02.004

24. Long J, Zhao L, Wu K, Zhong W, Xie C. Analysis of the Current Situation of the Joint Decision-making of Doctors and Patients in a Cancer Hospital. Hosp Admin J Chin PLA. 2019;26:101-108.

25. Hoerger M, Chapman BP, Mohile SG, Duberstein PR. Development and psychometric evaluation of the Decisional Engagement Scale (DES-10): A patient-reported psychosocial survey for quality cancer care. Psychol Assess. 2016;28(9):1087-1100. doi:10.1037/pas0000294

26. Luo B, Xiao S. Reliability and validity for Chinese version of the 9-item Shared Decision Making Questionnaire. Zhong Nan Da Xue Xue Bao Yi Xue Ban. 2019;44(7):823-829. doi:10.11817/j.issn.16727347.2019.180316

27. National health commission of the Peoples Republic of China. Notice of the Ministry of Health on Printing and Distributing the Standards for the Evaluation of Tertiary General Hospitals (2011 Edition); 2011.

28. Liu Y, Li T, Guo L, Zhang R, Feng X, Liu K. The Mediating Role of Sleep Quality on the Relationship Between Perceived Stress and Depression Among the Elderly in Urban Communities: A Cross-Sectional Study. Public Health. 2017;149:21-27. doi:10.1016/ j.puhe.2017.04.006

29. Brislin RW. Back-Translation for Cross-Cultural Research. J Cross Cult Psychol. 1970;1(3):185-216. doi:10.1177/135910457000100301

30. Wu ML. Questionnaire Statistical Analysis Practice. Chongqing University Press; 2009:257.

31. Shi J, Mo X, Sun Z. Content validity index in scale development. Zhong Nan Da Xue Xue Bao Yi Xue Ban. 2012;37(2):152-155.
32. Hazar KZ, Pala OO, Karabicak GO, Citaker S. Cross-cultural adaptation, validity, and reliability of the Turkish version of the Patient-Rated Elbow Evaluation. Clin Rheumatol. 2019;38(11):3289-3295.

33. Liu HJ, Tao XF, Wang XX. Health measurement scales: a practical guide to their development and use (5th edition). Aust $N$ Z J Public Health. 2016;40(3):294-295. doi:10.1111/1753-6405.12484

34. Dong JQ, Liu W, Liu HJ, Tao XF, Wang XX. Status of fear of progression and path analysis of influencing factors in elderly patients with postoperative prostate cancer. Modern Preventive Med. 2019;46(4):760-763.

35. Zou GY. Sample size formulas for estimating intraclass correlation coefficients with precision and assurance. Stat Med. 2012;31 (29):3972-3981. doi:10.1002/sim.5466

36. Guo L, Jones MC, Liu Y, Yv S, Zhu Y, Guo Y. Cross-cultural validation of the Student Nurse Stress Index Scale: A descriptive survey targeting student nurses in China. J Affect Disord. 2019;251 (31-38):31-38. doi:10.1016/j.jad.2019.03.017

37. Gao H, Söderhamn U, Zhang L, Cui H-X, Liu K. Reliability and validity of the Chinese version of the Nutritional Form For the Elderly. Public Health Nutr. 2015;18(14):2559-2564. doi:10.1017/ S1368980014003267

38. Sousa VD, Zauszniewski JA, Bergquist-Beringer S, Musil CM, Neese JB, Jaber AF. Reliability, validity and factor structure of the Appraisal of Self-Care Agency Scale-Revised (ASAS-R). J Eval Clin Pract. 2010;16(6):1031-1040. doi:10.1111/j.1365-2753.2009.01242.x 39. Haesebaert J, Adekpedjou R, Croteau J, Robitaille H, Légaré F. Shared decision-making experienced by Canadians facing health care decisions: a Web-based survey. CMAJ Open. 2019;7(2):E210E216. (). doi:10.9778/cmajo.20180202

40. Rose A, Soundy A, Rosewilliam S. Shared decision-making within goal-setting in rehabilitation: a mixed-methods study. Clin Rehabil. 2019;33(3):564-574. doi:10.1177/0269215518815251

41. Zhai H, Lavender C, Li C, Wu H, Gong N, Cheng Y. Who decides? Shared decision-making among colorectal cancer surgery patients in China. Support Care Cancer. 2020. doi:10.1007/s00520-020-05391-3

42. Shi BF, Zhou LL, Zheng MY. Analysis of the demand of cancer patients for the right to know and its influence on the treatment attitude. Chin J Pract Nurs. 2011;27(13):61-62.

43. Hua XX, Sun XJ, Zhao DL, et al. Correlation analysis of treatment methods and medical expenditures of cancer patients in five counties of Shandong Province. J Shandong Univ. 2018;56(6):69-75,82.
Patient Preference and Adherence

\section{Publish your work in this journal}

Patient Preference and Adherence is an international, peer-reviewed, open access journal that focusing on the growing importance of patient preference and adherence throughout the therapeutic continuum. Patient satisfaction, acceptability, quality of life, compliance, persistence and their role in developing new therapeutic modalities and compounds to optimize clinical outcomes for existing disease states are major areas of interest for the journal. This journal has been accepted for indexing on PubMed Central. The manuscript management system is completely online and includes a very quick and fair peer-review system, which is all easy to use. Visit http:// www.dovepress.com/testimonials.php to read real quotes from published authors. 